\title{
The PEER Collaborative: Supporting engineering education research faculty with near-peer mentoring unconference workshops
}

\author{
Dr. Alice L Pawley, Purdue University, West Lafayette
}

Alice L. Pawley is an associate professor in the School of Engineering Education with affiliations with the Women's Studies Program and Division of Environmental and Ecological Engineering at Purdue University. She has a B.Eng. in chemical engineering (with distinction) from McGill University, and an M.S. and a Ph.D. in industrial and systems engineering with a Ph.D. minor in women's studies from the University of Wisconsin-Madison. She runs the Feminist Research in Engineering Education (FREE, formerly RIFE) group, whose diverse projects and group members are described at the website http://feministengineering.org/. She can be contacted by email at apawley@ purdue.edu.

\section{Dr. Adam R Carberry, Arizona State University}

Adam R. Carberry, Ph.D., is an Assistant Professor at Arizona State University in the Fulton Schools of Engineering. He earned a B.S. in Materials Science Engineering from Alfred University, and received his M.S. and Ph.D., both from Tufts University, in Chemistry and Engineering Education respectively. Dr. Carberry has been a member of PEER since the first workshop held in 2011.

Dr. Monica E Cardella, Purdue University, West Lafayette

Maria-Isabel Carnasciali, University of New Haven

Maria-Isabel Camasciali is Assistant Professor of Mechanical Engineering at the Tagliatela School of Engineering, University of New Haven, CT. She obtained her Ph.D. in Mechanical Engineering from Georgia Tech in 2008. She received her Bachelors of Engineering from MIT in 2000. Current engineering education research focuses on understanding the nontraditional student experiences, motivations, and identity development. Other research interests involve validation of CFD models for aerospace applications as well as optimizing efficiency of thermal-fluid systems.

Dr. Shanna R. Daly, University of Michigan

Dr. Jenna L Gorlewicz, Southern Illinois University Edwardsville

Jenna L. Gorlewicz received her BS in mechanical engineering from Southern Illinois University Edwardsville (Edwardsville, IL) in 2008, before pursuing her $\mathrm{PhD}$ in mechanical engineering at Vanderbilt University, where she worked in the Medical and Electromechanical Design (MED) Laboratory. At Vanderbilt, she was a National Science Foundation Fellow and a Vanderbilt Educational Research fellow. Jenna then returned to her alma mater, SIUE, as a faculty member in the Mechanical and Industrial Engineering Department in Fall 2013. Her research interests are in the design and assessment of haptic devices, human-machine interfaces, and robotic systems, with applications in both education and medicine.

\section{Dr. Geoffrey L Herman, University of Illinois, Urbana-Champaign}

Dr. Geoffrey L. Herman is a visiting assistant professor with the Illinois Foundry for Innovation in Engineering Education. He earned his Ph.D. in Electrical and Computer Engineering from the University of Illinois at Urbana-Champaign as a Mavis Future Faculty Fellow and conducted postdoctoral research with Ruth Streveler in the School of Engineering Education at Purdue University. His research interests include creating systems for sustainable improvement in engineering education, promoting intrinsic motivation in the classroom, conceptual change and development in engineering students, and change in faculty beliefs about teaching and learning. He is a recipient of the 2011 American Society for Engineering Education (ASEE) Educational Research and Methods Division Apprentice Faculty Grant. He helps steer the College of Engineering Dean's Strategic Instructional Initiatives Program and helps direct the Academy for Excellence in Engineering Education at the University of Illinois.

Dr. Morgan M Hynes, Purdue University, West Lafayette 
Dr. Morgan Hynes is an Assistant Professor of Engineering Education at Purdue University. He received his B.S. in Mechanical Engineering and Ph.D. in Engineering Education (both at Tufts University). In his research, Hynes explores the use of engineering to integrate academic subjects in K-12 classrooms. From close observations of classroom teaching and learning, he studies how students come to understand what engineering is and how learners conceptualize and engage in engineering and design. Specific research interests include design metacognition among learners of all ages; the knowledge base for teaching K-12 STEM through engineering; broadening the contexts of engineering activities to broaden participation and engagement; and teaching engineering. He has worked with a number of Boston Public Schools in integrating engineering activities into their curriculum.

\section{Dr. Shawn S Jordan, Arizona State University, Polytechnic campus Dr. Nadia N. Kellam, University of Georgia}

Nadia Kellam, Associate Professor in the College of Engineering at the University of Georgia, is codirector of the interdisciplinary engineering education research CLUSTER. In her research, she is interested in understanding how engineering students develop their professional identity, the role of emotion in student learning, and synergistic learning. She designed the environmental engineering synthesis and design studios and is now developing the design spine for the new mechanical engineering program. She is engaged in mentoring early career faculty and a recent research project uncovers the narratives of exemplar engineering faculty that have successfully transitioned to student-centered teaching strategies.

Dr. Micah Lande, Arizona State University, Polytechnic campus

Dr. Matthew A Verleger, Embry-Riddle Aeronautical Univ., Daytona Beach

Matthew Verleger is Assistant Professor in Freshman Engineering at Embry-Riddle Aeronautical University. He has a BS in Computer Engineering, an MS in Agricultural \& Biological Engineering, and a PhD in Engineering Education, all from Purdue University. Prior to joining the Embry-Riddle faculty, he spent two years as an Assistant Professor of Engineering Education at Utah State University. His research interests include Model-Eliciting Activities, online learning, and the development of software tools to facilitate student learning.

\section{Dr. Dazhi Yang, Boise State University}

Dazhi Yang is an Assistant Professor in the Educational Technology Department at Boise State University. Prior to coming to Boise State, she was a postdoctoral researcher and instructional designer in the School of Engineering Education at Purdue University. Her current research focuses on instructional strategies and online course design techniques for STEM subject areas, especially engineering and science; instructional strategies for teaching difficult and complex science and engineering concepts with the assistance of technology; and teacher education and professional development. Due to her interest and background in teacher education, Dr. Yang designed, developed and coordinated the K-12 Online Teaching Endorsement Program at Boise State. Dr. Yang was a featured researcher of the Association for Educational Communications and Technology (AECT) International Convention and the Young Researcher Award recipient from the American Educational Research Association (AERA). Recently she also received the Effective Practice Award (in online and eLearning) from the Sloan-Consortium. 


\title{
The PEER Collaborative: Supporting engineering education research faculty with near-peer mentoring unconference workshops
}

\begin{abstract}
The PEER Collaborative National Network is a national peer mentoring network for early career tenure-track or mid-career tenured faculty who conduct and are primarily evaluated based on their research related to engineering education. This paper discusses the development, logistics, and outcomes of two PEER workshops built around a community of practice framework. Data from internal and external evaluations are presented to provide insights into aspects that worked well and aspects that need further development. Additionally, by reflecting on the workshops, participants crafted vignettes describing the-impact the PEER workshops had on their personal and professional lives. The paper concludes with a discussion on the future of PEER (and potential spin-off groups from the PEER cohorts), and the changes that will be made in future workshops. Recommendations are provided for other organizers interested in developing successful "near peer" groups to address specific community needs.
\end{abstract}

\section{Introduction}

In March 2009, a small group of colleagues across the engineering education research community came together as a peer mentoring community. A shared focus was on being evaluated for tenure based primarily on their engineering education research performance. The group of 12 developed and held a self-organized and self-funded retreat at Pine Mountain Resort State Park in Kentucky. For two full days, they talked in pairs and small groups about "thorny problems" they were wrestling with in their work. They reviewed each others' papers and grant proposals, problem-solved around issues working with difficult graduate students and developing complicated IRB applications, and discussed strategies for making interdisciplinary connections. These conversations, interspersed with recreational activities, built trust between the participants, which formed the foundation for peer-mentoring relationships. These relationships have not only continued but have grown deeper and expanded to include more people, including a few recently-tenured faculty now contemplating the new target of promotion to full professor. Naming themselves the PEER (Pine mountain Engineering Education Research) Collaborative, this group has continued to meet regularly at our major disciplinary conferences, and has strengthened relationships through online interactions via email, Skype, and a private Facebook group.

The group decided to expand the PEER Collaborative structure because of its perceived effectiveness and utility to the original group. Two national workshops, developed using the theoretical framework of communities of practice (Lave \& Wenger, 1991; Kimble \& Hildreth, 2008), have been held to evaluate whether this peer-mentoring structure may be useful to other early or mid-career faculty who are isolated (geographically or functionally) at their institutions from more senior faculty who are experienced in engineering education research. These 
workshops were funded by the National Science Foundation, held in in August 2011 and June 2013, and were collaboratively designed for a broader group of tenure-track and recently tenured engineering education faculty members.

This paper discusses the development, logistics, and outcomes of these workshops built around the community of practice framework. We present data from internal and external evaluations to provide insights into what worked and what needs further development. We include vignettes from participants reflecting on the PEER workshops and the effects the PEER events had on their personal and professional lives. The paper concludes with a discussion on the future of PEER and its relationship with other developing groups (including GEECS for graduate students and the EER Leaders for mid-career scholars groups), a discussion of the changes that will be made in future workshops, and recommendations for other organizers about developing successful "near peer" groups to address specific community needs.

\section{The need for peer mentoring in EER}

Over the last decade, there has been a change in the landscape of engineering education research. This change can be seen through a number of significant events in the engineering education community, including the reinvigoration of the Journal of Engineering Education's publication

mission, ${ }^{1}$ ASEE's Year of Dialogue ${ }^{2}$, the articulation of a set of research areas to structure future engineering education research agendas, ${ }^{3}$ and a plethora of editorials calling for the birth of a new discipline or the value of different forms of engineering education research. ${ }^{4,5}$ These events laid the intellectual groundwork for the growth of a new formal discipline of engineering education. Their momentum increased the hiring of engineering education faculty where tenure is granted based primarily on research performance. ${ }^{6}$ These positions emerged in a variety of different departments including engineering, education, and even newly established engineering education departments. Furthermore, new funding programs focused on engineering education research at the National Science Foundation have given faculty a vehicle for performing such work. Overall, the engineering education research community over the last decade has mobilized financial and human resources to generate an exciting, diverse, and, in many respects, new research discipline.

The growth in numbers of tenure-track faculty members who are evaluated primarily on their research performance in engineering education along traditional metrics of funding, publications, and graduate students graduated has been particularly exciting over the last eight years. However, most faculty have been hired into assistant professor positions, generating an imbalance in the blend of faculty ranks normally present in academic departments -- indeed, by virtue of their "start-up" situation, engineering education departments have been structured where assistant professors constitute the plurality (if not the majority) of members, followed by the number of associate professors, and then finally by full professors. This is the reverse of what is common in established academic departments. 
The imbalance of assistant to full professors engaged in engineering education research projects and programs places particular strain on assistant professors. Most are faced with working on their teaching and research with insufficient guidance and mentoring, while adapting to a new work environment. Faculty who are either in imbalanced departments or who exist in isolation at their institutions often find themselves both with leadership and service responsibilities considered unusual in established programs (e.g., chairing the graduate admission and curriculum committee, developing departmental policies and bylaws, running major research centers, and serving on strategic planning committees). The few senior faculty with expertise in engineering education tend to either be too sought after nationwide or are otherwise engaged to be able to spend much time with junior faculty. The imbalance makes it difficult to receive professional mentoring from established leaders.

In addition to this imbalance, there have been few faculty members nationwide who have gained tenure based on their engineering education research (although this number has dramatically increased in the last 2-3 years). More common is to find tenured faculty members who have transitioned into engineering education research after receiving tenure for their technical research. Furthermore, few institutions have any tenure guidelines or best practices for junior faculty engaged primarily in engineering education research. Tenure packages submitted in more traditional Colleges of Engineering must educate the college and department-level promotion and tenure committees about how to assess the value and quality of educational research as well as calibrate their expectation of funding sources and success. Often this burden falls on the tenure candidates themselves.

These challenges are urgent to address, as junior faculty are just starting to attempt tenure and promotion and the critical mass of assistant professors are soon to begin submitting tenure and promotion materials. Junior faculty at these institutions were hired for their promise and potential in a field beginning to establish itself using the same markers as conventional disciplines. We need to have a mechanism to pool knowledge between junior faculty across distributed locations and between isolated faculty members. We also need to build capacity among early and middle-career faculty in order to build critical mass around this new intellectual community of engineering education faculty members. Developing new mentoring frameworks and practices is an important way to link current junior faculty with successfully tenured faculty.

\section{Literature Background}

For this project we have adopted Lave and Wenger's Community of Practice (CoP) model as the theoretical framework for the design of the workshop. ${ }^{7}$ Communities of practice are groups of people who share a common concern, common practice, or a passion for something they do. These communities learn and produce solutions together as the community members interact with each other. There are three primary components that each CoP must entail: 
- The domain: A CoP has an identity defined by a shared domain of interest. In other words a CoP is not just a group of friends or a club of people. In the context of our workshop, the domain is engineering education research.

- The community: In varying degrees of participation, community members engage in joint activities and discussions, help each other, and share information in their domain. The community we have built is composed of junior, pre-tenure, and recently tenured scholars. The next generations of engineering education researchers are included and mentored as part of the community.

- The practice: Members of a community are practitioners (e.g., engineering education teachers, researchers, etc.). The practice we define involves the key responsibilities of faculties including research, teaching, and service.

This theory of CoP provides insights on new ways of thinking about learning from social participation. The characteristics of CoP, particularly its "informal" nature, make it hard to design, maintain, and assess in a systematic way. To overcome these challenges and initiate effective community, Lave and Wegner suggest:

1. identifying potential members (organizational, individual, other community) and helping them come together as a community of practice, and

2. assessing the value of a community of practice by listening to members' stories in a systematic way.

This first item was accomplished through the PEER Collaborative workshops themselves. The second we address through this paper.

\section{Workshops' participants and structure}

In this section, we describe the demographics of participants in the two PEER workshops and discuss the structure of the workshops held in August 2011 and June 2013.

First PEER Workshop: Athens, GA in August 2011

Twenty-four participants considered "near peers" - faculty and staff from engineering education, engineering, education, and design programs - attended the first official workshop (Table 1). Applications were required of all participants to ensure that all attendees considered themselves primarily evaluated based on engineering education research productivity. Almost $80 \%$ of participants were assistant professors, while two were associate professors, and two were researchers who were intending to apply for a faculty position. The majority of participants were women (over 60\%), and most came from departments of engineering education (almost 60\%).

The first workshop provided approximately 20 hours of professional development and mentoring over a day and a half, with activities and discussions designed to dynamically adapt to 
Table 1: First PEER Workshop participant demographics (August 2011, N = 24)

\begin{tabular}{|l|l|c|c|}
\hline Category & Description & $\mathbf{N}$ & $\mathbf{\%}$ \\
\hline \multirow{3}{*}{ Faculty rank } & Associate professor & 3 & $12.5 \%$ \\
\cline { 2 - 4 } & Assistant professor & 19 & $79 \%$ \\
\cline { 2 - 4 } & Other & 2 & $8 \%$ \\
\hline \multirow{2}{*}{ Gender } & Female & 15 & $62.5 \%$ \\
\cline { 2 - 4 } & Male & 9 & $37.5 \%$ \\
\hline \multirow{2}{*}{$\begin{array}{l}\text { Institution or department } \\
\text { type }\end{array}$} & Engineering education & 14 & $58 \%$ \\
\cline { 2 - 4 } & Disciplinary engineering & 2 & $33 \%$ \\
\cline { 2 - 4 } & Education & 2 & $8 \%$ \\
\hline
\end{tabular}

participants' needs. Topics discussed ranged from professional development for both tenuretrack and tenured faculty, developing reading, writing and publication strategies, discussing the development of engineering education research as a field, strategies for mentoring undergraduate and graduate students, balancing work and family life, and other issues. The workshops included guided activities, such as the use of visual images as a starting point for discussing participants' roles within engineering education and their institutions. The conversations were governed by the "law of two feet," borrowed from unconference structures ${ }^{8,9}$ : if participants found themselves neither learning nor contributing to others' learning, they were obliged to find somewhere else where they could learn or contribute. Participants were also encouraged to spend their time productively even if that meant leaving a main topic discussion to meet with people for smaller discussions. Discussions were animated and people took to heart the obligation to seek out opportunities to learn or help others learn.

The NSF workshop grant paid for the workshop location, materials, travel for the organizing team, and lodging and meals for all the participants.

Second PEER Workshop: Atlanta, GA June 2013

Eighteen participants similarly considered "near peers" - faculty and staff from engineering education, engineering, education, and design programs - attended the second workshop (Table 2). Applications were required of all participants to ensure that all attendees considered themselves primarily evaluated based on engineering education research productivity. Twelve of the eighteen participants attended first PEER workshop. Nearly $75 \%$ of participants were assistant professors; two were associate professors and two were researchers intending to apply for a faculty position. The group was split nearly equally by gender, but only one third of the group came from departments of engineering education, compared with nearly $60 \%$ in the first PEER workshop. 
Table 2: Second PEER Workshop participant demographics (June 2013, N = 15*)

\begin{tabular}{|l|l|c|c|}
\hline Category & Description & $\mathbf{N}$ & $\mathbf{\%}$ \\
\hline \multirow{4}{*}{ Faculty rank } & Associate professor & 2 & $13 \%$ \\
\cline { 2 - 4 } & Assistant professor (2 or more years of experience) & 5 & $33 \%$ \\
\cline { 2 - 4 } & Assistant professor (fewer than 2 years experience) & 6 & $40 \%$ \\
\cline { 2 - 4 } & Other & 2 & $13 \%$ \\
\hline \multirow{3}{*}{ Gender } & Female & 8 & $53 \%$ \\
\cline { 2 - 4 } & Male & 7 & $47 \%$ \\
\hline \multirow{3}{*}{$\begin{array}{l}\text { Institution or department } \\
\text { type }\end{array}$} & Engineering education & 5 & $33 \%$ \\
\cline { 2 - 4 } & Disciplinary engineering & 1 & $40 \%$ \\
\cline { 2 - 4 } & Education & 3 & $7 \%$ \\
\cline { 2 - 4 } & Other & $20 \%$ \\
\hline
\end{tabular}

* The number of participants here is only 15 as this was the number of people who completed the demographic information request.

The second workshop provided approximately 15 hours of professional development and mentoring over a day and a half following the American Society for Engineering Education Annual Conference being held in Atlanta, GA. A compressed set activities and discussions were designed and used to dynamically adapt to participants' interests. Topics discussed ranged sharing strengths and weaknesses, and making connections between those people who had particular weaknesses to those who had strengths in those areas; a photo elicitation activity where participants reflected on their jobs as faculty by selecting an artwork that represents their job; tricks of the trade to various difficulties in small programs, small departments, or engineering contexts; and visioning where each member wanted to be in 5 years. More unstructured conversations happened during the afternoon unconference sessions that took place outside of the hotel's conference space and conversations included advice to secure a CAREER grant, how to balance life and work, how to prepare a strong tenure dossier, strategies for 3rd year reviews, advice for successful grant collaborations, what to do after you receive funding, and how to apply standards-based grading. The smaller group (compared to the previous workshop) afforded deep, rich conversations and individual written reflection where all were able to both learn and contribute to others' learning. Similarly to the first workshop, conversations were governed by the "law of two feet," and participants were encouraged to spend their time productively.

The NSF workshop grant paid for the workshop location, materials, and meals for all the participants, and up to $\$ 360$ for hotel for two nights and travel.

\section{Outcomes of PEER Workshops: Formal evaluation}

Workshop evaluations focused on the success of the workshops in meeting the main workshop goals. These goals included developing, supporting, and augmenting networks of faculty members who are working at US institutions and are evaluated for tenure or promotion primarily 
on their engineering education research performance. In the following subsections we discuss evaluation data from both 2011 and 2013.

Evaluation from First PEER Workshop (Athens, GA August 2011)

Three types of data were analyzed to understand impacts of the 2011 workshop: 1) observational data by a third non-participant party during the workshop, 2) document data collected through session notes and take-aways recorded by participants during the workshop, and 3) survey data collected through an assessment instrument administered online twice after the workshop.

The observational data were synthesized in the form of a story. The "storyteller," (who was the project's the external evaluator, and who sat in on many of the sessions), reported the major theme of tensions involved in junior faculty needing to push boundaries and forge paths in an evolving field such as engineering education research (EER). She structured her report within the framework offered by the Carnegie Initiative on the Doctorate on the development of an intellectual community: ${ }^{10}$ having a shared purpose, being diverse and multigenerational, being flexible and forgiving, and being respectful and generous. The external evaluator determined that the structure of the PEER workshop and its participants exhibited these four characteristics throughout the workshop, and so recommended that the PEER community see itself as a dynamic intellectual community and use the Carnegie framework as a guide in ongoing collaborative and professional development initiatives.

Notes collaboratively, although somewhat haphazardly, collected during group discussions were analyzed for key take-aways from the workshop. These take-away notes were categorized into three primary benefits recognized by participants: 1) specific resources, including books, papers, people who could help, and other resources; 2) specific problems to consider, including avoiding burnout, balancing work and the rest of life, new needs, "now what?" (i.e. a conversation of newly tenured faculty who now needed to rethink their career goals), reading research, too many responsibilities, and writing; and 3) strategies for tackling these problems and achieving success, including learning to be gentle with yourself, building community, figuring out your story, maintaining your focus, making time, staying organized, investing in setting up systems, and working the system. The content of these sessions, although not formally structured, were well aligned with the organizers' intents, and the original grant proposal.

An evaluation survey was sent to participants immediately after the workshop and included key questions related to the value and usefulness of the workshop as well as short-term and long-term benefits to the participants (Table 3). Overall, the data allow us to conclude that the workshop attendees thought their time during the workshop was well spent. They were satisfied with the quality of mentoring they received and the quality of mentoring they provided. 
Table 3: Experiences after the first PEER workshop

\begin{tabular}{|l|c|c|c|}
\hline Since attending the PEER workshop... & $\begin{array}{l}\text { Never } \\
\text { (none) }\end{array}$ & $\begin{array}{l}\text { Some (1-2x) or } \\
\text { Often (> 2x) }\end{array}$ & $\begin{array}{l}\text { Regularly } \\
\text { (weekly) }\end{array}$ \\
\hline $\begin{array}{l}\text { I have had conversations (online, in person, by email) with } \\
\text { someone "new" I met at the workshop. }\end{array}$ & 3 & 14 & 0 \\
\hline $\begin{array}{l}\text { I have had conversations (online, in person, by email) with a } \\
\text { PEER colleague that I knew before the workshop }\end{array}$ & 1 & 13 & 12 \\
\hline $\begin{array}{l}\text { I have received mentoring or other help from someone who } \\
\text { attended the workshop. }\end{array}$ & 4 & 12 & 0 \\
\hline $\begin{array}{l}\text { I have provided mentoring and/or other help to someone who } \\
\text { attended the workshop. }\end{array}$ & 3 & 14 & 14 \\
\hline $\begin{array}{l}\text { I have shared ideas I gained during the PEER workshop with } \\
\text { others who were not at the PEER workshop. }\end{array}$ & 1 & 2 \\
\hline
\end{tabular}

Participants also indicated that after the workshop, they felt more confident in areas such as managing projects and tasks. Patterns identified as key outcomes by participants are shown in Table 4 with quotes.

Table 4: Quotes from experiences after the first PEER workshop

\begin{tabular}{|c|c|}
\hline Theme & Most Memorable Experience (emphasis added) \\
\hline \multirow[t]{5}{*}{$\begin{array}{l}\text { Mentoring \& } \\
\text { Contributing }\end{array}$} & $\begin{array}{l}\text { Enjoyed gathering with colleagues to discuss mentoring students and post docs. } 2 \\
\text { Reasons: Felt like had something to contribute and was gratifying to be together with } \\
\text { like-minded colleagues. }\end{array}$ \\
\hline & Learned that mentoring can be an important learning influence. \\
\hline & $\begin{array}{l}\text { Having a slightly senior colleague offering to be available as a mentor for me and } \\
\text { receiving thanks from my colleagues for small tips and suggestions. }\end{array}$ \\
\hline & $\begin{array}{l}\text { Getting stickers : ) [Authors' note: this was part of an appreciation activity to give stickers } \\
\text { to people from whom you learned something.] }\end{array}$ \\
\hline & $\begin{array}{l}\text { Seeing the face of an aspiring faculty member light up after offering my personal } \\
\text { information and a promise to help if help is needed. Good to know that people really } \\
\text { believe that we're out there to help. }\end{array}$ \\
\hline \multirow[t]{4}{*}{ Connecting } & $\begin{array}{l}\text { Enjoyed connecting with colleagues about experiences as faculty members and discuss } \\
\text { the state of engineering education research. }\end{array}$ \\
\hline & $\begin{array}{l}\text { The opportunity to meet and interact with a number of different early career engineering } \\
\text { education researchers. }\end{array}$ \\
\hline & $\begin{array}{l}\text { The group discussions and individual one-on-one conversations were extremely } \\
\text { memorable. The individual stories will stick. }\end{array}$ \\
\hline & $\begin{array}{l}\text { The REAL conversations about real experiences and strategies for approaching } \\
\text { challenges. }\end{array}$ \\
\hline
\end{tabular}




\begin{tabular}{|c|c|}
\hline & $\begin{array}{l}\text { Learning more about people I didn't know well and gaining very positive perceptions } \\
\text { about them. }\end{array}$ \\
\hline & $\begin{array}{l}\text { As a new faculty member, I feel like there is a community of people that I am a part of. } \\
\text { This is not always something I feel at my institution. }\end{array}$ \\
\hline \multirow[t]{3}{*}{$\begin{array}{l}\text { Vision \& } \\
\text { Planning }\end{array}$} & $\begin{array}{l}\text { Remembering that it's important to take the time up front to plan, organize etc. so that I } \\
\text { can be intentional about my days, weeks, months, semesters. }\end{array}$ \\
\hline & $\begin{array}{l}\text { Heard the same theme reinforced over and over: Define your vision and then align your } \\
\text { day-to-day. }\end{array}$ \\
\hline & $\begin{array}{l}\text { Realizing that there's no silver bullet missing or secret to be found out yet and that with } \\
\text { others I am responsible for creating that path. Also sharing concerns and getting support } \\
\text { on personal, intimate concerns about how being new faculty can change the relationship } \\
\text { with my partner. }\end{array}$ \\
\hline \multirow[t]{2}{*}{$\begin{array}{l}\text { Self-awareness } \\
\text { \& Confidence }\end{array}$} & $\begin{array}{l}\text { Reflection on how much I have learned in the past } 4 \text { years and how far I have come, } \\
\text { resulting in overall greater confidence in myself. }\end{array}$ \\
\hline & I am not a grad student anymore! I am a researcher!!! \\
\hline
\end{tabular}

A second follow-up evaluation survey distributed two months after the workshop was completed by 17 of the 24 participants and focused on actions and perceptions related to their own identity as engineering education researchers and their engineering education research work.

All who completed the follow-up survey indicated benefiting from the workshop in diverse ways. Almost all also had had on-going conversations with "old" and "new" colleagues who attended the workshop and had shared information gained from the workshop with someone who had not attended the workshop. When asked about a key highlight realized about the workshop in the two months between the workshop and the follow-up evaluation, participants reported benefitting in diverse ways:

- Attending "helped me reframe how I think about things" particularly with respect to writing and submitting papers.

- Staying in contact with other participants via Skype or Facebook for many reasons including just to "cheer up" each other.

- Feeling "more connected" to engineering education research, or even to one's own department.

- Enjoying being both a mentor and mentee.

- Feeling "less isolated" and "validated" in one's fears and questions.

- "Starting the semester energized" with an attitude of making changes, feeling more "invigorated" as a researcher, feeling excited to know there are others in the same place.

- "Paying it forward," sharing ideas (within the bounds of the house rules) with those who weren't able to attend. 
- Feeling more able to ask for help, feeling like "I have a support group".

- Identifying more people who need mentorship, and with specific ideas on how I could help them.

- Connecting with more senior people particularly with respect to getting feedback on proposals.

- Finding a group of "critical friends".

- Getting concrete ways of dealing with current problems.

All sources of data gathered about this workshop pointed to multiple successful outcomes for participants, having immediate and long term impacts on their success and feelings of success as engineering education researchers.

Evaluation from Second PEER Workshop (Atlanta, GA, June 2013)

We conducted a more focused evaluation of the 2013 workshop. Participants were sent an online survey (based on the original survey for the first workshop) two months after the workshop that focused on (1) their experiences after the workshop, and (2) how to make the PEER community and workshops more sustainable.

Participants were asked a series of questions to understand their experiences after the workshop that began with, "Since attending the PEER workshop..." The results are summarized in Table 5.

Table 5: Experiences after the second PEER workshop

\begin{tabular}{|l|c|c|c|c|}
\hline Since attending the PEER workshop... & $\begin{array}{l}\text { Never } \\
\text { (none) }\end{array}$ & $\begin{array}{l}\text { Some (1- } \\
\text { 2x) }\end{array}$ & $\begin{array}{l}\text { Often } \\
\text { (>2x) }\end{array}$ & $\begin{array}{l}\text { Regularly } \\
\text { (weekly) }\end{array}$ \\
\hline $\begin{array}{l}\text { I have had conversations (online, in person, by email) with } \\
\text { someone "new" I met at the workshop. }\end{array}$ & 5 & 7 & 3 & 0 \\
\hline $\begin{array}{l}\text { I have had conversations (online, in person, by email) with a } \\
\text { PEER colleague that I knew before the workshop }\end{array}$ & 0 & 1 & 11 & 3 \\
\hline $\begin{array}{l}\text { I have received mentoring or other help from someone who } \\
\text { attended the workshop. }\end{array}$ & 4 & 9 & 2 & 0 \\
\hline $\begin{array}{l}\text { I have provided mentoring and/or other help to someone who } \\
\text { attended the workshop. }\end{array}$ & 2 & 8 & 4 & 1 \\
\hline
\end{tabular}

We also asked participants to report how they believed the workshop impacted them in the two months since. The questions each began with, "As a result of the PEER workshop..." Table 6 displays participant responses.

Table 6: Outcomes from the second PEER workshop

\begin{tabular}{|l|c|c|c|}
\hline As a result of the PEER workshop & No & Maybe & Yes \\
\hline I have had continued benefits from the PEER workshop. & 0 & 1 & 14 \\
\hline I feel less isolated at my home institution. & 1 & 3 & 11 \\
\hline $\begin{array}{l}\text { I feel less isolated in the EER community as a result of attending the workshop } \\
\text { and meeting colleagues. }\end{array}$ & 1 & 1 & 13 \\
\hline I feel I have learned from or benefitted from a pool of knowledge created at the & 1 & 0 & 14 \\
\hline
\end{tabular}




\begin{tabular}{|l|c|c|c|}
\hline workshop. & & & \\
\hline $\begin{array}{l}\text { I feel I have contributed to a pool of mentoring knowledge about being a faculty } \\
\text { member }\end{array}$ & 0 & 6 & 9 \\
\hline
\end{tabular}

Finally, we asked participants to describe in an open-ended format what they gained from the experience. We highlight some quotes from participants below, which are consistent with the themes of benefits that resulted from the first workshop, triangulating the value of the experience. This is especially important because the second workshop was shorter.

- "[I gained] a great sense of community. I left the workshop encouraged and energized to pursue some goals that had previously been daunting."

- "[I gained] a network of colleagues with whom I can collaborate, exchange feedback on papers and proposals, talk about concerns and celebrate successes."

- "[I gained] Perspective on potential challenges and issues I will face as I begin a tenuretrack position."

- "[I gained] broader perspectives on what engineering education programs look like at different universities and a better understanding of how these programs are striving to be defined."

- "[I gained] seeds of collaboration. Since the workshop, I have begun sharing and receiving early stage grant proposals and journal articles from the PEER participants. These interactions have been informative and immensely valuable."

- "I made connections within my intellectual community and built social capital with peers."

Even in the short timeframe of only two months, most participants had already experienced the benefits and value of the PEER workshop firsthand. One question for future exploration is to understand why some participants aren't experiencing the benefits as greatly as others. We want this community to have great impacts for all, so even though there are few "no/ never" responses, we want to figure out how to eliminate those answers completely.

The assessment of the second workshop also opened up the question of how the PEER community should proceed moving forward. Past participants needed to discuss what contributions participants should make to future PEER events, and ideas they had to sustain the effort. Table 7 summarizes participant plans to participate in the future of PEER and the bullet list below provides further elaboration on some of the responses. Each of the questions began with, "As a result of your experience at the PEER workshop..."

Table 7: Sustainability of the PEER community (second workshop only)

\begin{tabular}{|c|c|c|c|}
\hline As a result of your experience at the PEER workshop... & No & Maybe & Yes \\
\hline $\begin{array}{l}\text { I would encourage other engineering education research faculty members or researchers to } \\
\text { participate in future PEER workshops. }\end{array}$ & 0 & 1 & 14 \\
\hline $\begin{array}{l}\text { I plan to attend next year's PEER workshop at Purdue after the ASEE conference in } \\
\text { Indianapolis. }\end{array}$ & 0 & 1 & 14 \\
\hline
\end{tabular}




\begin{tabular}{|l|l|l|l|}
\hline I would be willing to help plan a future PEER workshop & 2 & 1 & 12 \\
\hline I would be willing to pay a fee and my hotel to attend a PEER workshop in the future. & 1 & 3 & 11 \\
\hline
\end{tabular}

The following comments help illuminate the numbers in Table 7:

- "One potential downside I see to placing a fee on the PEER workshop is that the workshop seemed to attract a good number of faculty from institutions where "having sufficient funds" to travel and attend conferences is challenging. Having this diversity at the workshop, however, is part of what makes it so unique and successful, and it would be a shame to see that diminish due to financial reasons."

- "Free is always best, but I have found so much value in these workshops that I would pay to attend."

- "I would lean toward a system of "first time is free or cheaper" to attract new colleagues and participants."

- "In my opinion, the benefits of the workshop are far greater than the fees suggested- i.e. it's worth it!"

This diversity of perspectives should be taken into account in conversations about the future of PEER and subsequent PEER events.

\section{Outcomes of PEER Workshops: Illustrative vignettes}

Past participants from both workshops were asked in December 2013 to provide reflections of how the PEER workshop(s) made a difference for them. The selected vignettes include a variety of participants across different positions and different types of departments. These vignettes serve as first-hand data illustrating the ways this community of practice has impacted these different participants long after the completion of the workshops.

Vignette 1: Assistant Professor in a Department of Engineering; attended the second workshop. "Having been a newcomer to the PEER group and relatively new in the engineering education community, I was excited but nervous about attending my first PEER workshop. Being a new assistant professor in a traditional engineering discipline, I had fears that I would not be a part of the group or perhaps viewed as an outsider that doesn't belong. The minute the PEER workshop started, however, those fears faded, and by the end of the workshop, I felt much more confident about being an active contributor to this community. This welcomed confidence boost was just one of the impacts of PEER. Throughout the workshop, I found myself engaging and obtaining advice from colleagues of diverse backgrounds and at various points in their careers. It struck me then that this workshop was unlike others I had attended. Somehow, this workshop fostered a refreshingly different atmosphere, focused, but flexible; open, but tight-knit; simple, but rich. I vividly remember one of the morning activities where all participants had to walk around and observe various paintings chosen by the moderators. We then had to choose a painting that we related to in the context of our career, or an aspect of it. This activity opened up a number of rich 
discussions on the highs and lows of a faculty career, work-life balance, and the like. What struck me most was everyone's willingness to share detailed accounts of experiences, but to also take these personal reflections and relate them back into a professional context of engineering or engineering education as a discipline and a career. From these discussions, I learned a great deal about the field of engineering education and its evolving landscape as well as numerous successful strategies for navigating the faculty career path. Perhaps the largest impact from PEER, however, were the networks and collaborations I established from the event. Not only do I keep in continued contact with these connections, but I found that they have greatly enriched the diversity of my network, offering unique perspectives and backgrounds to learn from both professionally and personally. I left the PEER workshop feeling like I had established a supportive network of colleagues who all shared a common mission of contributing to and enhancing engineering education.”

Vignette 2: Assistant Professor in a Department of Education; attended second workshop. "My passion and one of my main research interests is engineering education. As a faculty member whose home department is in the College of Education, I'm working and collaborating with faculty in engineering at my own institution as well as at other institutions. There is a disadvantage for me in terms of intellectual exchanges with colleagues with a similar passion for engineering education research at my home institution. The 2013 PEER workshop I attended in Atlanta, GA provided me opportunities to experience such intellectual exchanges, not only during the workshop, but most importantly beyond and after the workshop. The workshop allowed me to have a better overall picture of the current trends in terms of research topics and the development and growth of engineering education as a field. For example, I had the opportunity to hear about other engineering education researchers' work and the issues they were facing at their respective institutions. The PEER workshop also allowed me to seek advice and feedback on my CAREER grant proposal and to build a closer relationship with some of the top engineering education researchers in the field. I have attended many similar professional development and networking workshops and events, but I would say the PEER workshop was one of the most beneficial workshops for me given my unique situation. Also because of the PEER workshop, I have made a few more friends and now have more people whom I can exchange ideas and information with at different conferences."

Vignette 3: Research Professor in a Department of Engineering; attended second workshop. "Before I attended the PEER workshop, I had met many of the participants at conferences or other events, but had at best shallow relationships with most of them. The PEER workshop provided an excellent opportunity for me to deepen these relationships and gain confidence and accountability in my work. Since the workshop, I have begun swapping articles and proposals with several other participants of PEER to give and receive feedback on drafts. I have received candid and honest feedback that has been invaluable. I have also been held accountable to meet my internal paper deadlines so that I keep writing even when other responsibilities are clamoring 
for my attention. I now have twice as many papers in submission than I have ever had prior to PEER. I attribute this level of feedback and accountability to the quality of relationships that I built during the workshop (and the quality of my peers!). Additionally, I have had ongoing discussions with members of PEER to collaborate on future papers and proposals. Two of my current proposals are being formulated or written now directly because of PEER. Attending the PEER workshop has also helped me reformulate my strategies for success. I have always struggled with time management and overcommitting. I have had some success adopting strategies suggested to me by other PEER attendees, such as using the program Wunderlist to track my various projects. Tracking these activities has helped me better identify how I spend my time and what I need to start doing for future success. While I have attended many networking and professional development events, the PEER workshop has yielded the most ongoing, tangible fruit in my scholarly pursuits."

Vignette 4: Assistant Professor in a Department of Engineering; attended both workshops. "I attended the first PEER workshop the week before I began my first tenure-track position. The experience was a wonderful precursor allowing me to enter the position focused and prepared for what was to come. I feel like many jobs are trial by fire and it can often times be difficult to find support. This gathering provided an outlet for such support. Amazingly, that support has remained even after the workshops. The most valuable information I gathered from the two workshops was to make sure you stay true to yourself and keep a balanced life. These two ideas have guided my actions through 3 successful years. I've explicitly made time to be the best teacher I can be. I've conducted and disseminated research that I wanted to do. I've also made time to enjoy my life outside of work. This approach has lead me down a path of successfulness and happiness."

Vignette 5: Associate Professor in a Department of Engineering Education; attended both workshops gaining tenure between workshops. "I found I always wanted to spend time talking with colleagues about my professional context, but at conferences we were always too busy, too booked. PEER allowed me access to colleagues who had identified similar needs for mentoring, and who had committed time to coming to a workshop to just talk about anything and everything. Through PEER interactions, I have met new colleagues, and strengthened collaborations with existing ones. The development of these relationships have allowed me to call colleagues for help by email, phone, and Facebook weeks and months after we leave the workshops, and I am glad to have been called on in return. As a result of PEER conversations, I have collaborated with PEER colleagues on papers, gotten advice on my teaching, and served on others' grant proposals. I am in a book group with some PEER members, and I'm helping organize another workshop with other PEER members. I am grateful for this community and honored to help contribute to it." 
In conjunction with the formal evaluation data, these vignettes further highlight how the PEER workshops successfully created a professional community of practice in the field of engineering education research. A number of participants, newer to the field, noted how that the workshop gave them an opportunity to meet like-minded faculty members who they were able to establish lasting and professionally meaningful relationships. More experienced faculty noted that the workshops provided easier access to busy colleagues who are difficult to meet with during large, highly structured conferences. Whether it was establishing new relationships or deepening existing ones, participants shared that they were able to collaborate on publishing and grantwriting activities that are often difficult in this emerging field. Participants also expressed gratitude for opportunities to discuss strategies for the tenure and promotion process in a field where the standard engineering measures for tenure and promotion success do not quite fit. Similarly, conversations about attaining work-life balance benefited participants.

\section{Conclusions}

Based on these evaluation data, we feel justified in claiming that the PEER workshops have helped develop and support a dynamic intellectual community for junior and mid-level faculty and researchers in the engineering education field. Participants not only considered the time during the workshop well spent, but also reported a positive impact on their teaching, research, and service in the field of engineering education some months after the workshop. PEER workshop participants report having benefited in many aspects from this community through social participation, such as having one's fears and questions validated and feeling more confident as a researcher. The workshops have helped participants better connect with others within the engineering education research field, including, even after the workshops, reaching out to others for feedback and advice on publication and grant writing.

There remains the issue that benefits are somewhat uneven, however, with some participants reporting weaker benefits than others, and experiencing no gains in some areas. This may be something to probe in future workshop designs.

The PEER Collaborative Network has, therefore, developed a way for its community members to share resources, concerns, strategies for tackling different problems including balancing work and life, and giving and receiving mentoring. Key aspects of its process include the notion of near-peer mentoring rather than senior-junior mentoring, and the unconference format that supported whatever relevant conversations people wanted to have.

Although the NSF grant supporting this work is now over, the PEER Collaborative is currently co-organizing a self-funded workshop to be held after ASEE 2014 in Indianapolis. The listserv and Facebook page remain active, and the group has a strategy for incorporating new members through recommendations from existing members, to make sure the group remains focused on the needs of people primarily evaluated on their engineering education research productivity. 
However, based on our evaluation data, for some people, the future of PEER is dependent on adequate funding from home institutions or external sources. Conversations on future workshops should dig deeper into strategies for continuous support of this community.

In addition, there are other similarly-developing groups with which we believe PEER needs to more intentionally connect, including GEECS (Graduate Engineering Education Consortium for Students, for graduate students; https://www.facebook.com/phdconsortiuminengineering education) and the EER Leaders (Engineering Education Research Leader Networkshop group, mid-career faculty who focus on engineering education research but who are interested in moving into leadership positions in the EER community). Some PEER participants were involved with GEECS as graduate students, and some PEER people are now tenured and therefore are connecting with the EER Leaders; together, these three organizations could provide peer-mentoring support for entering $\mathrm{PhD}$ students through associate professors, and should perhaps be leveraged together to provide cross-class support in addition to their successful within-class mentoring. At the time of writing, the PEER group is discussing ways we might be able to cross-fertilize at the next 2014 workshop; we will present the results of this discussion at ASEE.

However, across all these aspects, we advocate that communities looking for ways to organize themselves think more broadly about who can serve junior faculty as mentors: our peermentoring strategy is not perfect, but has certainly demonstrated that it is better than doing without. The unconferencing spirit of putting the responsibility of having useful conversations on the shoulders of participants also helped people find value in insights offered by others. We recommend the paired use of these ideas for others planning workshops or looking for mentoring opportunities.

\section{Acknowledgements}

We thank those who attended either PEER Collaborative Network workshop and shared their stories, concerns and experiences. This material is based upon work supported by the National Science Foundation under Grant No. 1129455. Any opinions, findings, and conclusions or recommendations expressed in this material are those of the authors and do not necessarily reflect the views of the National Science Foundation.

\section{Bibliography}

1. $\quad$ Felder, R. M., Sheppard, S. D. \& Smith, K. A. A New Journal for a Field in Transition. J. Eng. Educ. 94, $7-$ 10 (2005).

2. Wormley, D. N. A Year of Dialogue Focused on Engineering Education Research. J. Eng. Educ. 95, 179 (2006).

3. National Engineering Education Research Colloquies. The Research Agenda for the New Discipline of Engineering Education. J. Eng. Educ. 95, 259-261 (2006). 
4. Haghighi, K., Smith, K. A., Olds, B. M., Fortenberry, N. L. \& Bond, S. The Time is Now: Are We Ready for Our Role? J. Eng. Educ. 97, 119-121 (2008).

5. Haghighi, K. Quiet No Longer: Birth of a New Discipline. J. Eng. Educ. 94, 351-353 (2005).

6. School of Engineering Education Strategic Plan. 2011, (2009).

7. Lave, J. \& Wenger, E. Situated learning: Legitimate peripheral participation. (Cambridge University Press, 1991).

8. Wikipedia contributors. Open Space Technology. 2011, (2011).

9. Wikipedia contributors. Unconferences. 2011, (2011).

10. Walker, G., Golde, C. M., Jones, L., Bueschel, A. C. \& Hutchings, P. The Formation of Scholars: Rethinking Doctoral Education for the Twenty-First Century. (Jossey-Bass, 2008). 